\title{
Numerical Modelling of Gaseous Fuel Combustion Process with the Stepwise Redistribution of Enriched Combustion Air
}

\author{
Miroslav Rimár ${ }^{1}$, Ján $\mathrm{Kizek}^{1, *}$, and Andrii Kulikov ${ }^{1}$ \\ ${ }^{1}$ Department of Process Technique, Technical University of Košice, Faculty of Manufacturing \\ Technologies with a seat in Prešov, Bayerova 1, 08001 Prešov, Slovakia
}

\begin{abstract}
The authors of this paper present the results of simulations for burner system design changes in the smelting aggregate. Based on the analysis of the existing burner system in the experimental aluminium smelting equipment, changes in the burner design were proposed. The obtained results are presented in tables and figures. The properties of the proposed changes were investigated using the simulation software ANSYS. The simulations confirmed the suitability of the proposed system for shortening the flame length and intensification of the mixing of gaseous media.
\end{abstract}

\section{Introduction}

Burner systems are the source of heat in heat generators, which in most cases use gaseous fuels. At present, such units are a subject to increase demands due to emission reductions and energy efficiency. These demands stem from the EU's energy policy and form one of its pillars.

Heat aggregates are of various constructions and have specific demands on heat sources. The authors Tatič and Lukáč in [1] briefly summarized the basic characteristics of industrial aggregates. Burner systems also have a great influence on the work of such units. Such an influence is also addressed by the authors in [2] where the ceiling burner system is described, and the flame flow keeps the flame close to the burners.

Changing the burner system leads to a change in the heat transfer to the charge. Furnace conditions such as temperature and heat transfer to the batch must be observed [3-6]. Proper combustion settings in burner systems will increase the life of the aggregates and reduce the amount of emissions produced [4,6]. Adjustment of combustion parameters is also possible using mathematical models and simulations. Combined computationalexperimental studies confirmed the possibility for thermal efficiency to increase in cases of industrial biomass boiler [7] in regeneration boiler for black liquor combustion [8] as well as in refinery furnaces [9].

\footnotetext{
*Corresponding author: jan.kizek@tuke.sk
} 


\section{Burner system design}

The authors proposed a new burner system for mixing enriched air with gaseous fuel, which is based on the existing burner system for melting aluminium described in [7].

The authors focused on two main design tasks:

1) Change the supply of oxidizing agent from co-current to tangential and thus change the dynamics of the mixing of gaseous media.

2) Redistribution of the oxidizing agent for gradual mixing with gaseous fuel by changing the geometry of the air nozzle. Modification of the burner geometry consists of placing the dividing insert cylindrical part in the air nozzle.

According to Equation (1) in [10], the burner geometry was designed based on the flame length. This relationship is especially valid for co-current supply of gaseous media for combustion in the burner. The validity of this relationship was confirmed on the basis of temperature field measurements by the authors in [11] in the combustion chamber of the experimental equipment.

The co-current burner of [10], designed for the melting chamber of the drum furnace, proves to be unsuitable for the short length of the melting chamber. Therefore, when increasing the power, it is necessary to shorten the flame length.

Figure 1 schematically shows the modifications of the burner also with the location of the dividing insert part in the air nozzle.

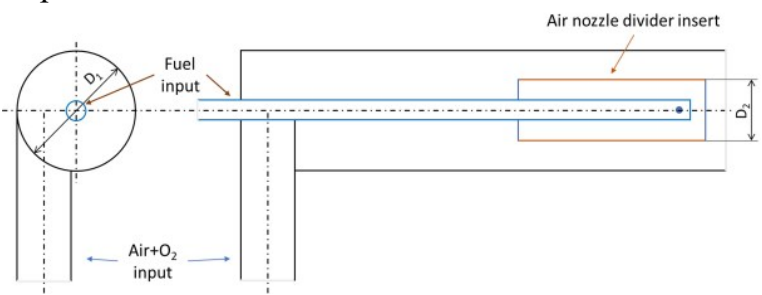

Fig. 1. Schematic design of burner modifications.

The dividing insert part is located in the mouth of the burner. Proposed burner adjustment solutions could address this shortcoming.

\section{Simulation model}

When designing a change in the geometry of the burner and the supply of the oxidizing agent used simulation using Ansys Fluent 19 software, in which a simulation model was also created.

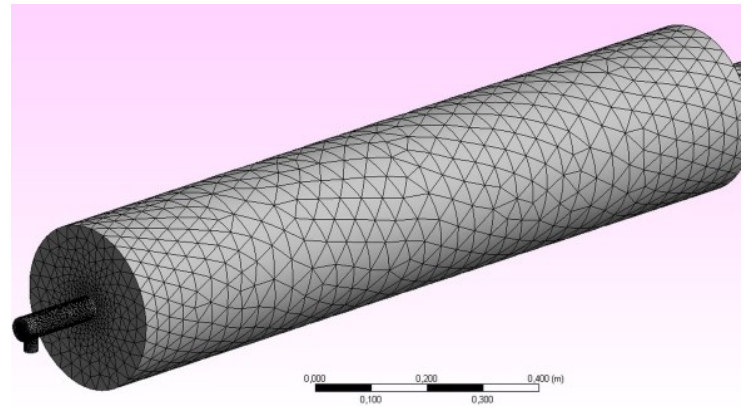

Fig. 2. Mesh of simulation model of burner and combustion chamber. 
The subject of the study is a model of a combustion chamber with burners installed in it (Figure 2). The combustion chamber has the shape of a cylinder. The exhaust duct is located opposite the burner.

The mathematical model network was created using Ansys Mesh (Figure 2). The model has 219978 elements. The proximity and curvature functions were used to increase the accuracy of the model. The orthogonal quality of the model was min. 0.27 for less than $0.11 \%$ of the elements and the Skewness was max. 0.74 for less than $0.09 \%$ of elements.

The boundary conditions of the walls are adiabatic. The input of fuel and oxidizer is solved through the flow inlet from the direction perpendicular to the cross-sectional area. The output of combustion products from the simulation model is solved using a pressure output.

As settings for the Ansys Fluent simulation software were used the energy equation model, turbulence realizable $\mathrm{k}-\varepsilon$ model, and radiation $\mathrm{p} 1$ model. The combustion process was made via PDF table. Fuel composition for simulation is at the Table 1.

Table 1. Fuel composition for simulation.

\begin{tabular}{|c|c|c|c|}
\hline & Methane & Propane & Butane \\
\hline$\%$ & 95 & 3 & 2 \\
\hline
\end{tabular}

The input parameters for simulation are at the Table 2.

Table 2. Simulation input parameters Parameter and values for the simulations performed.

\begin{tabular}{|c|c|c|}
\hline Parameter & \multicolumn{2}{|c|}{ Value } \\
\hline Air nozzle diameter $-\mathrm{D}_{1}, \mathrm{~mm}$ & 44 & 26 \\
\hline Fuel flow, $\mathrm{m}^{3} \cdot \mathrm{h}^{-1}$ & 1.32 & 1.32 \\
\hline Air flow, $\mathrm{m}^{3} \cdot \mathrm{h}^{-1}$ & 14.33 & 12.03 \\
\hline Oxygen mass fraction, \% & 21.00 & 25.00 \\
\hline Excess air & 1.1 & 1.1 \\
\hline
\end{tabular}

Baukal [12] from a literature review found that industrial applications use oxygen enrichment to less than $30 \mathrm{vol} . \%$. For this reason, a maximum air enrichment to an $\mathrm{O}_{2}$ content of 25 vol. $\%$ was considered for the simulations. This limit was determined due to the performed experimental measurements according to [13] and supplemented in [10] by own measurements. Increasing the oxygen content would lead to an increase of the combustion temperature and, as noted by the authors in $[14,15]$, also to an increase of the formation of $N O_{x}$ emissions.

\section{Results and discussion}

The design of the burner was based on the existing burner system for melting aluminium in a model of the tilting rotary furnace. The aim of the authors was to design a new burner system for mixing enriched air with gaseous fuel.

In the first simulations, the authors focused on unenriched air and the diameter of the air nozzle $D_{1}=44 \mathrm{~mm}$. In the original burner, a cocurrent air supply is considered. In the design for the simulations, the oxidant supply is tangential (Figure 1).

Figure 3 shows the results of a simulation of the flow of gaseous media with a tangential supply to the air nozzle. According to the speed of the streams calculations, it can be concluded that there was an intensive mixing of the gaseous fuel with the oxidizing agent. 


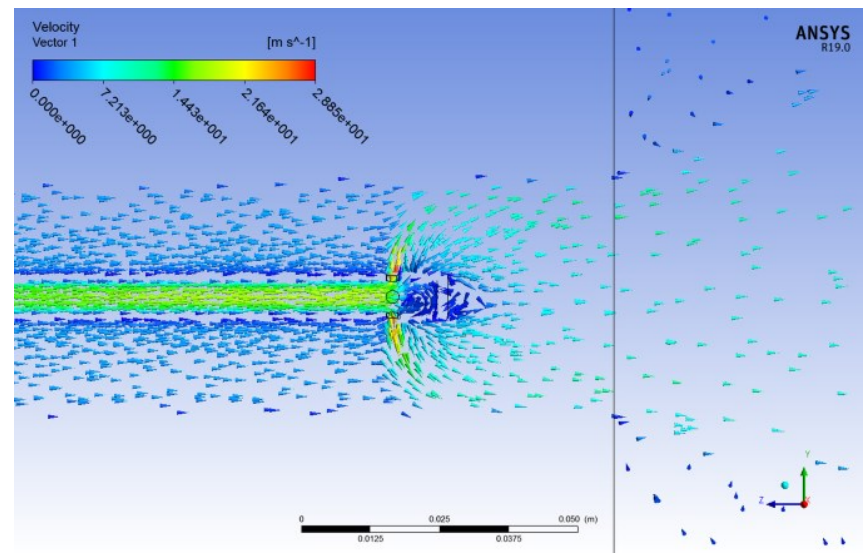

Fig. 3. Simulation of the flow of gaseous media without insert part $\left(D_{l}=44 \mathrm{~mm}\right)$.

Another research objective of the authors was, based on the redistribution of the oxidizing agent, to simulate the gradual mixing with gaseous fuel. The length of the partition insert was selected $65 \mathrm{~mm}$ and a diameter $D_{2}=20 \mathrm{~mm}$. The location of the insert part is at the mouth of the burner so that there is a gradual mixing of the divided stream of the oxidizing agent.

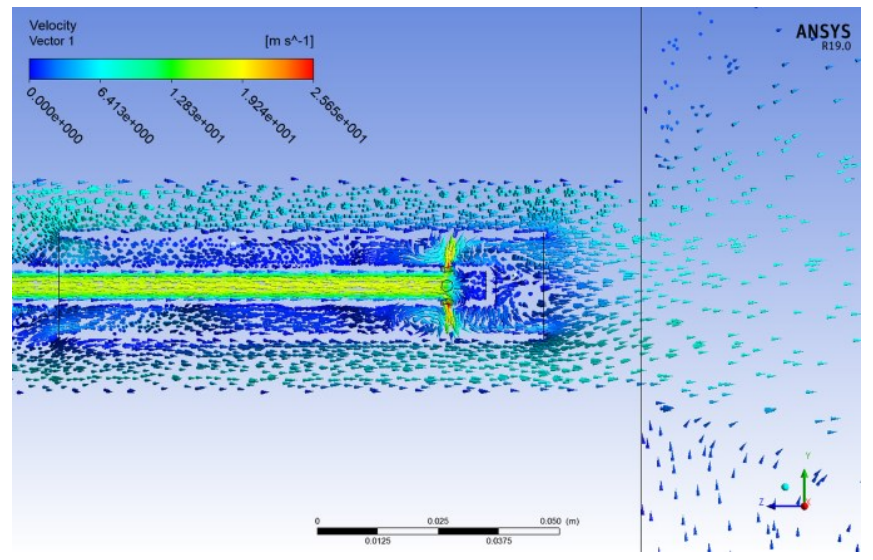

Fig. 4. Simulation of the flow of gaseous media with insert part $\left(D_{l}=44 \mathrm{~mm}, D_{2}=20 \mathrm{~mm}-\right.$ Ver.1.1).

From the simulation in Figure 4, it is possible to observe a change in the flow in the insert part. The flow of gaseous media inside the insert part does not coincide with the direction of the gases exit from the burner. The oxidizing agent is sucked into the interior of the dividing insert part and mixed with the gaseous fuel, thereby shifting the combustion to the fuel nozzle. This is an undesirable phenomenon that had to be eliminated due to possible damage to the burner mouth. For this reason, a new diameter of the dividing inserts $D_{2}=30 \mathrm{~mm}$ was chosen.

The result of the simulation is shown in Figure 5 using velocity vectors of gaseous media. From the simulation, it is possible to observe a change in the flow of the oxidizing agent in the insert part in the direction of the burner exit. 


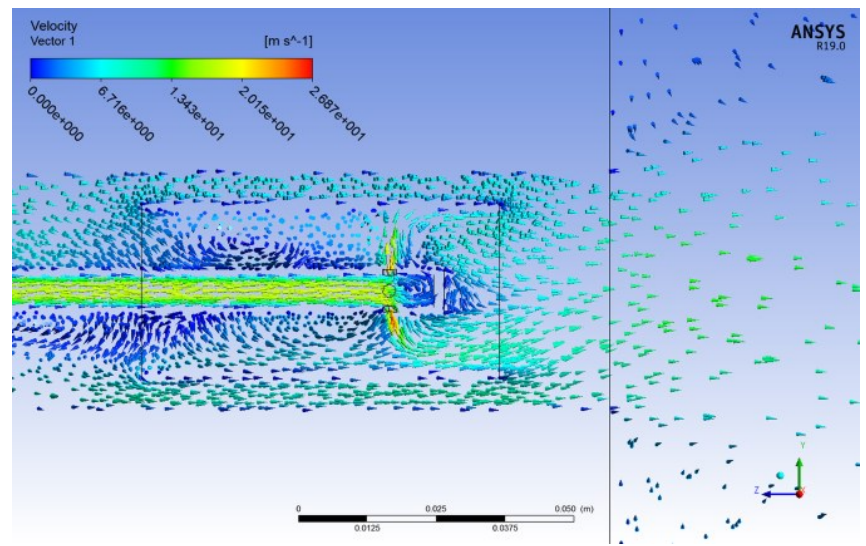

Fig. 5. Simulation of the flow of gaseous media with insert part ( $D_{l}=44 \mathrm{~mm}, D_{2}=30 \mathrm{~mm}$ - Ver.1.2).

For the further simulations, a smaller air nozzle diameter was considered due to air enrichment to 25 vol. $\% \mathrm{O}_{2}$ content. As in the first case, a simulation of the flow of gaseous media without insert part was performed. The result of the simulation is shown in Figure 6.

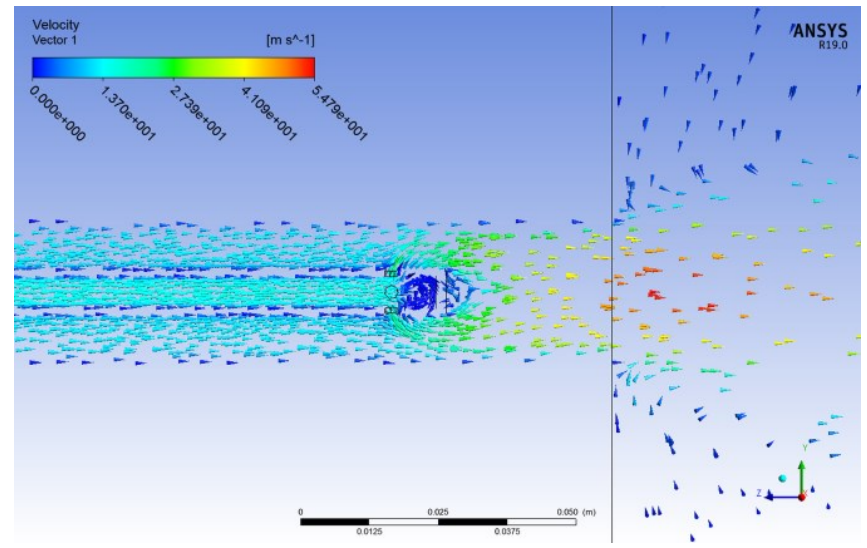

Fig. 6. Simulation of the flow of gaseous media without insert part $\left(D_{l}=26 \mathrm{~mm}\right)$.

Figure 6 shows the result of a simulation of the flow of gaseous media with a tangential supply to the air nozzle. Here again, the flux rates of the gaseous media can be concluded that there was more intense mixing of fuel gas with an oxidizing agent on the burner orifice.

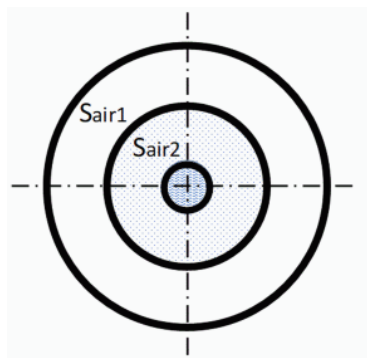

Fig. 7. Burner cross-section - divided areas of the air nozzle.

For the design of the insert part, a criterion was sought that would ensure correct flow in the insert part. Table 3 shows the ratio of diameters and areas (Figure 7) in the air nozzle. 
Table 3. Ratios of diameters and areas in the air nozzle.

\begin{tabular}{|c|c|c|c|}
\hline & Ver.1.1 & Ver.1.2 & Ver.2.1 \\
\hline $\mathrm{D}_{1}, \mathrm{~mm}$ & 44 & 44 & 26 \\
\hline $\mathrm{D}_{2} / \mathrm{D}_{1}$ & 0.4545 & 0.6818 & 0.6923 \\
\hline $\mathrm{S}_{\text {air } 2} / \mathrm{S}_{\text {air } 1}$ & 0.2892 & 1.0526 & 1.2174 \\
\hline
\end{tabular}

From the values given in Table 3 for the first air nozzle (Ver.1.1 and Ver.1.2), it was found that if the ratio of the areas $S_{\text {air }} / S_{\text {air } 1}$ is greater than 1 , then the flow in the manifold should be correct.

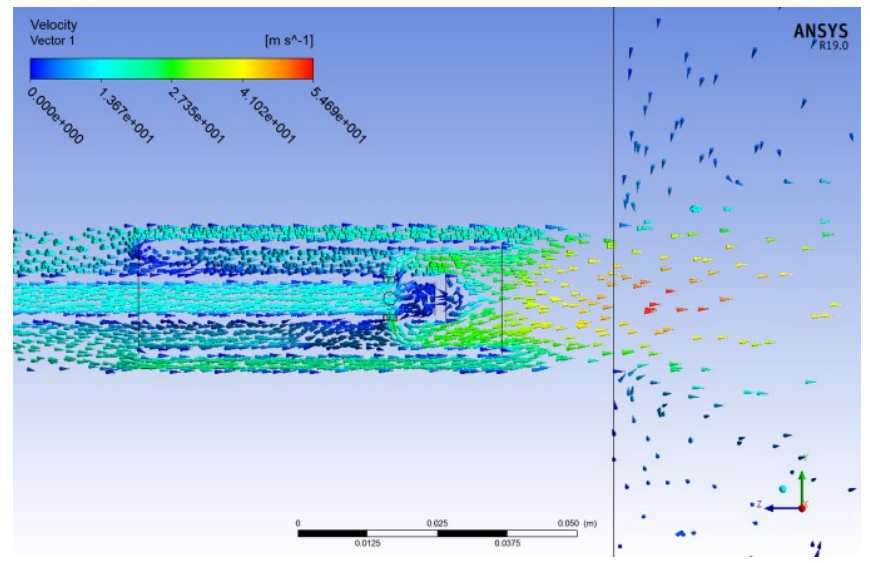

Fig. 8. Simulation of the flow of gaseous media with insert part ( $D_{l}=26 \mathrm{~mm}, D_{2}=18 \mathrm{~mm}$ - Ver.2.1).

Figure 8 shows the result of a simulation where ratio of areas of the insert part air nozzle was greater than 1 . From the analysis of the velocity vectors, it can be concluded that the flow direction in the insert part is correct and that the gaseous fuel with the oxidizing agent is intensively mixed at the burner orifice.

Table 4. Obtained results from simulations for 2 types of burner and 2 different oxygen contents in the oxidizing agent.

\begin{tabular}{|c|c|c|c|c|}
\hline $\mathrm{O}_{2}$ content in the air, $\%$ & 21 & 21 & 25 & 25 \\
\hline Air nozzle diameter $\mathrm{D}_{1}, \mathrm{~mm}$ & $44^{\text {a) }}$ & $44^{\mathrm{b})}$ & $26^{\text {a) }}$ & $26^{\text {b) }}$ \\
\hline The highest temperature, ${ }^{\circ} \mathrm{C}$ & 1600 & 1694 & 1669 & 1727 \\
\hline Medium temperature, ${ }^{\circ} \mathrm{C}$ & 1258 & 1574 & 1617 & 1627 \\
\hline Flame length, mm & 1000 & 700 & 350 & 250 \\
\hline $\mathrm{CO}_{2}, \mathrm{mg}^{-3} \mathrm{~m}^{-3}$ & 20250 & 20200 & 20250 & 20250 \\
\hline $\mathrm{CO}, \mathrm{mg}^{-3} \mathrm{~m}^{-3}$ & 42 & 35 & 28 & 28 \\
\hline $\mathrm{NO}, \mathrm{mg} \cdot \mathrm{m}^{-3}$ & 29 & 18 & 33 & 36 \\
\hline $\mathrm{O} 2, \mathrm{mg}^{-3}$ & 6400 & 6940 & 13750 & 13650 \\
\hline
\end{tabular}

a) without insert part

b) with insert part $(65 \mathrm{~mm})$

Table 4 shows the results obtained from simulations of the burners without and with the insert part. 
Owing to the insert part the highest temperature behind the burner as well as the mean temperature is increased. Comparing the flame length in both cases, the flame was shortened due to the more intensive mixing of gaseous media in the burner orifice.

In terms of emerging emissions, it can be observed that in the case without air enrichment, to reduce $C O$ and $N O$ emissions. This can be explained by the more intensive mixing of the gaseous media and a shorter mixing zone at the burner orifice.

In the case of air enrichment, it can be stated that although the flame length was shortened by more intensive mixing, the increase in temperature increased the amount of thermal $N O$ emissions. The amount of $C O$, in this case, is even lower, and with using the partition insert is unchanged.

\section{Conclusion}

The results of computer simulations confirmed the effect of changes in the oxidant supply and air nozzle geometry on the mixing intensity of gaseous media and the generation of emissions.

The analysis of simulation results confirms that:

-Insertion of the separating insert part into the air nozzle helped to adjust the flow of the oxidizing agent so as to shorten the flame and intensify the mixing of the gaseous media. The proof is the increased temperature behind the burner using a separating insert.

-Changing the dynamics of the flow in the air nozzle, by adjusting the supply of oxidizing agent, adjusted the flow of the resulting flue gases behind the burner. This change could intensify the circulation with flue gases on the charge and thus increase the intensity of heat exchange.

The performed simulations are only a partial solution of the proposed change of the burner construction. The authors state in [14] that the addition of oxygen changes the geometry and structure of the flame and therefore further research is needed.

For further simulations, the authors want to focus on monitoring the change in the parameter of the insert part, not only in diameter but also in its length and location with the respect to the gas nozzle.

This work was supported by the Slovak Research and Development Agency under the contract No. APVV-16-0192.

\section{References}

1. M. Tatič, L. Lukáč, Industrial furnace 1 furnace in metallurgy and mechanical engineering (in Slovak). (TU of Košice, Košice, 2009)

2. A. Varga, M. Tatič, L. Lazić, Metalurgija 48, 3 (2009)

3. K. Ferstl, M. Masaryk. Heat transfer (in Slovak). (STU in Bratislava, Bratislava 2011)

4. R. Pyszko, T. Brestovič, N. Jasminská, M. Lazár, M. Machů, M. Puškár, R. Turisová, Measurement, 75, NOV (2015) DOI: 10.1016/j.measurement.2015.07.052

5. M. Holubčík, N. Kantova, B. Červenka, J. Trnka, AIP Conf. Proc., 2118, 1(2019) https://doi.org/10.1063/1.5114743

6. J. Fík, Spalování plynných paliv a plynové hořáky (GAS s.r.o., Praha, 1998)

7. M. Variny, O. Mierka, Waste Forum, 3 (2018)

8. M. Variny, M. Blahusiak, J. Janošovský, M. Hruška, O. Mierka, Energy Effic., 12, 6(2019) DOI: 10.1007/s12053-019-09804-z 
9. M. Variny, M. Blahusiak, O. Mierka, Š. Godó, T. Margetíny, Energy Effic., 12, 7(2019) DOI: 10.1007/s12053-019-09808-9

10. R. Dzurňák, A. Varga, J. Kizek, G. Jablonský, L. Lukáč, Appl. Sci., 9, 8 (2019) https://doi.org/10.3390/app9081614

11. G. Jablonský, M. Pástor, R. Dzurňák, Enriching the combustible mixture with oxygen in practice (in Slovak). (TU of Košice, Košice, 2015)

12. C. E. Baukal Jr., Oxygen-Enhanced Combustion,2st ed. (CRC Press: New York, 2013)

13. S. Jepson, P.V. Kampen, Industrial Heating, 72, 6(2005)

14. A. Poskart, H. Radomiak, P. Niegodajew, M. Zajemska, D. Musiał, Arch. Metall. Mater., 61, 4 (2016) DOI: 10.1515/amm-2016-0309

15. Š. Papučík, R. Lenhard, K. Kaduchová, J. Jandačka, J. Koloničný, J. Horák. AIP Conference Proceedings 1608, 98 (2014) 